\title{
Multiple Leveling for Paddy Field Preparation with Double Axis Rotary Tillage Accelerates Rice Growth and Economic Benefits
}

\author{
Yifu Zhang ${ }^{1, *(\mathbb{D}}$, Jian Liu ${ }^{1}$, Wei Yuan ${ }^{1}$, Ruihong Zhang ${ }^{1,2}$ and Xiaobo Xi ${ }^{1,2} \mathbb{D}$ \\ 1 School of Mechanical Engineering, Yangzhou University, Yangzhou 225127, China; \\ MZ120190666@yzu.edu.cn (J.L.); MX120210538@yzu.edu.cn (W.Y.); 002674@yzu.edu.cn (R.Z.); \\ xbxi@yzu.edu.cn (X.X.) \\ 2 Jiangsu Engineering Center for Modern Agricultural Machinery and Agronomy Technology, \\ Yangzhou 225127, China \\ * Correspondence: zyfu@yzu.edu.cn
}

\section{check for} updates

Citation: Zhang, Y.; Liu, J.; Yuan, W.; Zhang, R.; Xi, X. Multiple Leveling for Paddy Field Preparation with Double Axis Rotary Tillage Accelerates Rice Growth and Economic Benefits. Agriculture 2021, 11, 1223. https:// doi.org/10.3390/agriculture11121223

Received: 1 November 2021

Accepted: 30 November 2021

Published: 3 December 2021

Publisher's Note: MDPI stays neutra with regard to jurisdictional claims in published maps and institutional affiliations.

Copyright: (c) 2021 by the authors. Licensee MDPI, Basel, Switzerland. This article is an open access article distributed under the terms and conditions of the Creative Commons Attribution (CC BY) license (https:// creativecommons.org/licenses/by/ $4.0 /)$.

\begin{abstract}
In the multiple cropping regions of southern China, straw returning has become a widely practiced agronomic measure for rice cultivation. However, excessive straw often leads to a high proportion of stubble in topsoil, which prolongs the leveling time of the paddy field and delays the transplanting date for rice seedlings. In particular, scholars in this region have successively improved multiple paddy field levelers to realize excellent straw returning and subsequent land preparation synchronously, but the economic benefit from land preparation to crop harvest was less reported. Therefore, this study carried out a 2-year rice cultivation experiments to compare the effects of paddy field preparation methods on rice growth and economic benefits within the same growing duration. Three treatments were designed: traditional tillage (TT), double axis rotary tillage (DR) and multiple operations for paddy field preparation (DR $+\mathrm{ML}$ ), with three repeats. The results showed that DR + ML treatment simplified the operation process while improving the quality of land preparation. Within the same growing duration, DR + ML treatment could reduce the paddy field preparation time and extend the growing time in the field by 5-6 days. Furthermore, in comparison to TT treatment, $\mathrm{DR}+\mathrm{ML}$ showed advantages in stimulating plant development, increasing dry matter accumulation (DMA), and thereby increasing rice yield by more than $12 \%$. The economic benefits were mainly reflected in saving operation cost of paddy field preparation and improving the output (grain yield), which can generally increase the total profit by $58 \%$. The implementation of this study can provide a reference for a simplified high yield cultivation technique in rice-related multiple cropping systems.
\end{abstract}

Keywords: rice cultivation; paddy field leveling; multiple preparation; crop growth; economic benefit

\section{Introduction}

In China, more than $75 \%$ of the rice (Oryza sativa L.) production is distributed in the southern multiple cropping area, mainly in rice-wheat, rice-coleseed and other multiple cropping systems [1]. Paddy field preparation is the first crucial working procedure after the previous crop harvest, which requires various operations successively such as basal fertilizing, water retting for farmland, returning straw by rotary tillage, and leveling, to prepare for the transplanting of rice seedlings. In this multiple cropping system, farmers have to complete the whole mechanical operations in a paddy field within a short crop rotation time to win adequate growing time for rice [2,3].

Proper land levelling in irrigated areas is a pre-requisite for judicious use for limited irrigation water $[4,5]$. Reviewing previous studies, high-quality land leveling at paddy fields may induce better management for fertilizer and water use in rice cropping [6-8]. Domestic research on paddy field leveling machinery has mainly been aimed at meeting the agronomic standard for flatness [9]. Then, high efficiency and composite leveling 
machinery was equipped with the application of laser, sensor and spatial information technology [10-12]. A laser-controlled paddy field levelling-beater was designed by Zhou et al. [13], while the grade of the levelling scraper was automatically controlled according to the vertical height and tractor roll angle. Aryal et al. [14] demonstrated the benefits in irrigation time by $10 \mathrm{~h} \mathrm{hm^{2 }}$ and crop yield by 7-9\% in laser-leveled fields. Furthermore, $\mathrm{Xu}$ et al. [15] designed a wide puddling and flatting machine for paddy fields, integrating tillage, soil crushing, puddling, burying stubble and flatting in one-time operation. Based on the global navigation satellite system (GNSS), Zhou et al. [16] designed an intelligent rotary tillage and leveling machine, which improved the stability and adaptability in the paddy field. Overall, current research on leveling machinery for paddy fields tended to focus on multiple operations, laser leveling, and self-adaptation by sensors [17-19].

However, under the multiple cropping cultivation systems of southern China, the large amount of straw often led to poor quality of mechanical returning into field. Recent studies rarely take into account this superabundant straw from previous crops. Wang et al. [20] designed a self-balancing paddy field leveler equipped with double axis rotary tillage, to explore combined multiple leveling and harmless straw returning. However, the economic benefit from land preparation to crop harvest was limited reported [21].

Therefore, we hypothesized that if paddy field preparation with three or more independent mechanical processes could be simplified and improved, it would be beneficial in saving leveling cost, promoting crop growth, thereby facilitating the economic benefit for rice cropping. In this study, a multiple paddy field preparation method was proposed to complete the basal dressing, straw returning, and land leveling successively at one time. Specifically, 2-year rice cultivation experiments were conducted in a rice-wheat double cropping system, double axis rotary tillage and multiple operations for paddy field preparation were applied to determine how they contribute to crop performance and economic profit. During each cropping season, the 100\% previous crop straw was incorporated into the field, surface flatness, plant height, dry matter accumulation (DMA), grain yield, soil bulk density and the thereby economic benefit were measured to evaluate the farmland response treated by straw double axis rotary tillage and multiple paddy field preparation.

Accordingly, the objective of this study was to investigate the impacts of multiple paddy field preparation under $100 \%$ straw returning condition on land leveling quality and crop growth, in particular to accomplish a quantitative assessment for the potential benefits, and to thereby optimize the paddy field preparation process, reduce mechanical operation cost and improve economic profit.

\section{Materials and Methods}

\subsection{Field Experimental Site and Soils}

Rice cultivation experiments were conducted from May 2019 to October 2020, at Jiangdu District, Yangzhou City, Jiangsu Province ( $\left.32^{\circ} 52^{\prime} \mathrm{N}, 119^{\circ} 73^{\prime} \mathrm{E}\right)$. The site belongs to the subtropical humid region, with $1220-\mathrm{mm}$ average annual precipitation, and a 227-day frost free period. Mean monthly temperature and precipitation during the year of cultivation experiments are presented in Figure 1. 


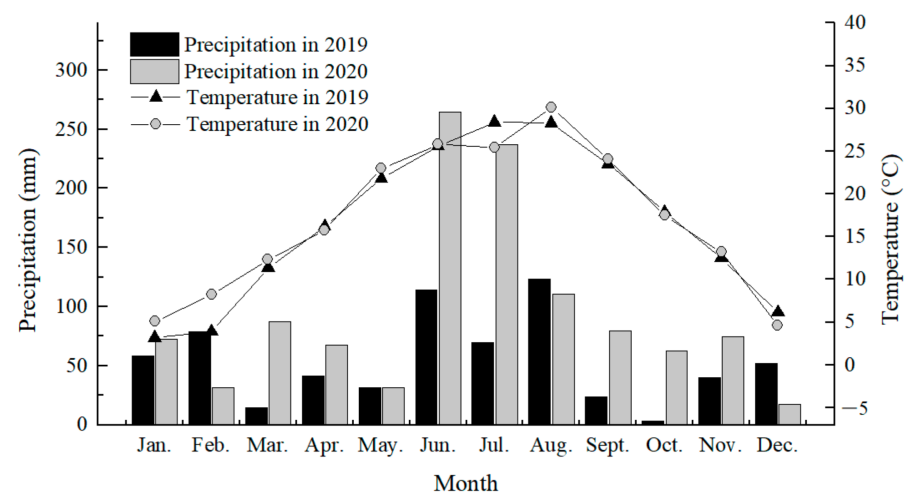

Figure 1. Mean monthly temperature and precipitation of experimental site in 2019 and 2020.

The soil in cultivated layer was defined as loamy clay with $39.6 \%$ sand $(0.02-<2 \mathrm{~mm})$, $22.2 \%$ silt $(0.002-<0.02 \mathrm{~mm})$, and $38.2 \%$ clay $(<0.002 \mathrm{~mm})$. The average soil bulk density was $1.35 \mathrm{~g} \mathrm{~cm}^{-3}$, with $35.3 \%$ field capacity (by weight). Before the experiment, original soil samples were collected and analyzed for chemical properties in May 2019 (Table 1).

Table 1. Soil chemical properties of cultivated layer prior to experiments.

\begin{tabular}{ccc}
\hline \multirow{2}{*}{ Items } & \multicolumn{2}{c}{ Soil Depth $\mathbf{( c m )}$} \\
\cline { 2 - 3 } & $\mathbf{0 - 1 5}$ & $\mathbf{1 5 - 3 0}$ \\
\hline Soil organic matter $\left(\mathrm{g} \mathrm{kg}^{-1}\right)$ & 23.8 & 20.5 \\
Alkaline-hydrolysable nitrogen $\left(\mathrm{mg} \mathrm{kg}^{-1}\right)$ & 42.0 & 39.6 \\
Available phosphorus (by Olsen, $\left.\mathrm{mg} \mathrm{kg}^{-1}\right)$ & 13.7 & 11.4 \\
Available potassium $\left(\mathrm{mg} \mathrm{kg}^{-1}\right)$ & 71.6 & 65.1 \\
$\mathrm{pH}$ & 7.7 & 7.4 \\
\hline
\end{tabular}

\subsection{Experimental Design and Equipment}

The site has been cultivated under a rice-wheat double cropping system for decades. The rice variety was Nanjing 9108, and the seeds were sown in late May and harvested in late October to ensure the same growing duration. The previous wheat harvest with stubble was performed in early June, and the wheat straw was smashed and evenly scattered on the land surface. After that, paddy field preparation was carried out. Paddy field preparation is the first crucial working procedure after the previous crop harvest, which requires various operations successively such as basal fertilizing, water retting for farmland, returning straw by rotary tillage, and leveling, making preparation for the transplanting of rice seedlings. In this study, 3 treatments, i.e., traditional tillage (TT), double axis rotary tillage (DR), and multiple leveling with double axis rotary tillage $(D R+M L)$ for paddy field preparation were designed, and the detailed working procedure was shown in Table 2. The three treatments were applied to $15 \mathrm{~m}$ wide and $30 \mathrm{~m}$ long field sections in a randomized block design, with three replicates, respectively. 
Table 2. Working procedure for paddy field preparation.

\begin{tabular}{|c|c|}
\hline Treatments & Mechanical Operations for Agronomic Arrangement \\
\hline $\begin{array}{l}\text { Traditional paddy field } \\
\text { preparation (TT) }\end{array}$ & $\begin{array}{l}\text { Complete the various operations successively, which } \\
\text { includes basal fertilizing, water retting for farmland, } \\
\text { returning straw by rotary tillage, and leveling, as the } \\
\text { control group. }\end{array}$ \\
\hline Double axis rotary tillage (DR) & $\begin{array}{l}\text { Returning straw into field by double axis rotary tillage, } \\
\text { and other working procedures were the same as TT. }\end{array}$ \\
\hline $\begin{array}{l}\text { Multiple operations for paddy field } \\
\text { preparation (DR + ML) }\end{array}$ & $\begin{array}{l}\text { After water retting for field, use a multiple levelling } \\
\text { machinery to complete basal fertilizing, straw returning } \\
\text { by double axis rotary tillage, and leveling at one time. }\end{array}$ \\
\hline
\end{tabular}

In this study, the mechanical equipment during traditional paddy field preparation involves fertilizer spreader, rotavator, and levelling machine, all of which are widely applied in local farming practice (Figure 2a). The working principle of double axis rotary tillage is shown in Figure $2 b$, the front axle is higher than the rear axle in a vertical direction. The entire tillage depth can strengthen surpass $20 \mathrm{~cm}$ as the rear axle tills the deeper soil on the basis of a front axle. Multiple-levelling machinery was designed based on a double axis rotary tillage method, integrating fertilizing, straw returning, and leveling to finish paddy field preparation in one-time operation. The prototype machine is shown in Figure 2c, and its design parameters are detailed in Reference [12].

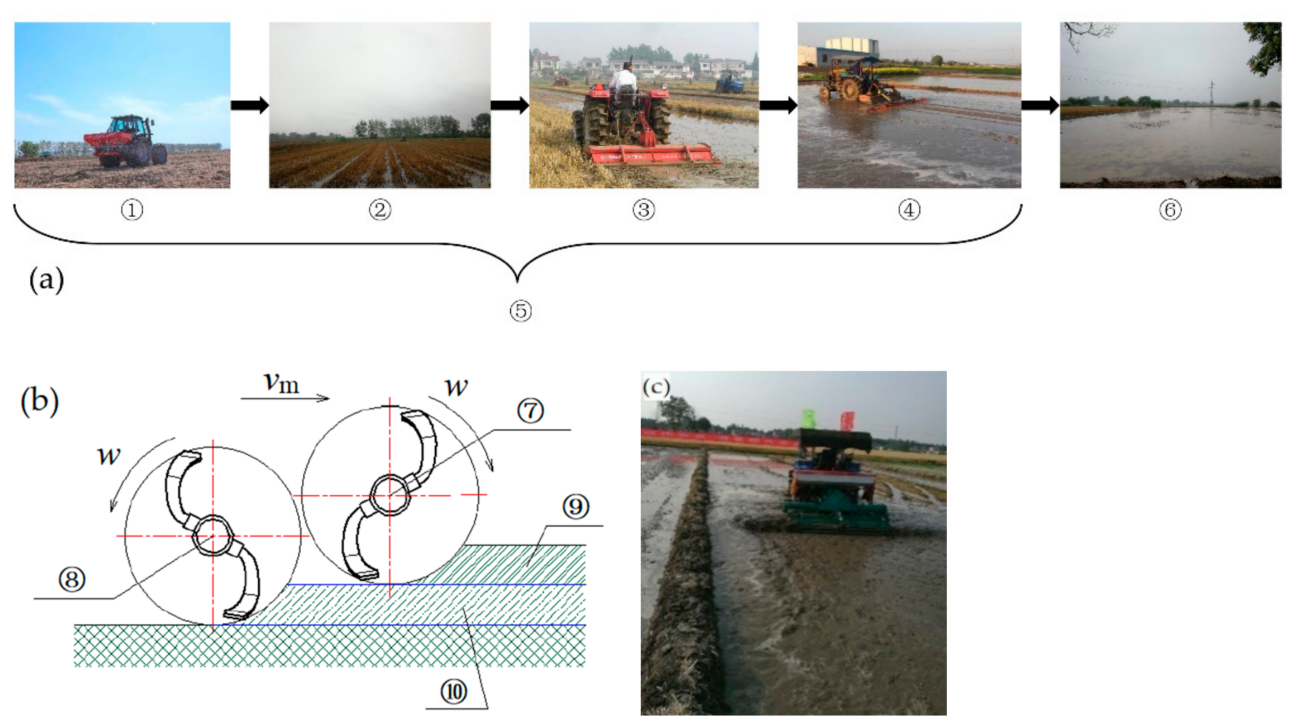

Figure 2. Equipment analysis for paddy field preparation, with (a) working process diagram of (5) traditional paddy field preparation, and its equipment, which requires (1) basal fertilizing, (2) water retting, (3) returning straw by rotary tillage, and (4) leveling, successively, to provide (6) leveled paddy lands for seedling transplanting; (b) working principle of double axis rotary tillage, in which the (7) front axle is higher than (8) rear axle in vertical direction, (9) first plowed soil layer, (10) deeper plowed soil layer, $w$ : rotation direction, $v_{\mathrm{m}}$ : forward direction of device; and (c) work scenario of multiple levelling machinery.

\subsection{Agronomic Management}

After paddy field preparation, rice seedlings were transplanted with a row spacing $25 \mathrm{~cm}$, and individual space $12 \mathrm{~cm} .270 \mathrm{~kg} \mathrm{hm}^{-2} \mathrm{~N}, 135 \mathrm{~kg} \mathrm{hm}^{-2} \mathrm{P}_{2} \mathrm{O}_{5}$, and $270 \mathrm{~kg} \mathrm{hm}^{-2}$ $\mathrm{K}_{2} \mathrm{O}$ were applied during each cropping season. The total nitrogen application rate was basal fertilizer:tillering fertilizer:panicle fertilizer $=4: 3: 3$. The tillering fertilizer and panicle fertilizer were used at 7 days after seedling transplanting and the fourth upper leaf stage, respectively. The irrigation and drainage system in the experimental area were well equipped, and each plot was separated by ridges to ensure independent water and fertilizer 
management. Pretilachlor (Syngenta Suzhou Crop Protection Co., Ltd., Suzhou, China), emulsifiable concentrate in $300 \mathrm{~g} \mathrm{~L}^{-1}$, at a rate of $450 \mathrm{~g} \mathrm{hm}^{-2}$ was applied to perform weed arrangement in accordance with the local agronomic specifications. Difenoconazole + propiconazole (emulsifiable concentrate in $300 \mathrm{~g} \mathrm{~L}^{-1}$ ) and chlorantraniliprole + thiamethoxam (40\% water dispersible granule) were incorporated at a rate of 90 and $60 \mathrm{~g} \mathrm{hm}^{-2}$, respectively, to control diseases and insect pests.

\subsection{Measurements}

According to the national standard "Flatting and puddling paddy field machine" (GB/T 24685-2009), 20 points along the forward direction were selected $2 \mathrm{~h}$ after paddy field preparation, and the vertical distance between the ground surface and horizontal datum surface was measured by a level instrument. Thus, the flatness of the leveled field is shown in:

$$
S=\sqrt{\sum(Y-\bar{Y})^{2} /(n-1)}, \bar{Y}=\sum Y / n
$$

where $S$ is the surface flatness, $\mathrm{cm} ; Y$ is the vertical distance between each test point and horizontal datum surface, $\mathrm{cm} ; \bar{Y}$ is the mean value of vertical distance, $\mathrm{cm} ; n$ is the number of test points.

Rice samples were collected at the jointing, heading and maturity stages, respectively. Five plants were selected from each plot to investigate plant height and DMA. At maturity stage, $1-\mathrm{m}^{2}$ of rice was harvested at random in each plot, and a measure of 1000-grain weight was oven-dried. The actual grain yield was calculated under standard moisture (14.5\%, by weight). Furthermore, agronomic characters such as panicles number, spikelets per panicle, and seed setting rate were investigated.

In the second cropping season, soil samples were collected 5 days after rice harvest in the second season (no rainfall event within the 5 days) to investigate the bulk density for 0-15, and 15-30 cm soil layers by the oven drying method. Throughout the experimental duration, all mechanical operating costs, agricultural input (water, seeds, fertilizers, etc.), labor cost and the field output were recorded to compare the economic benefit.

\subsection{Statistical Method}

SPSS analytical software (International Business Machines Corporation, New York, NY, USA) was used for statistical analysis to calculate mean values for each measurement. Multiple comparisons were made to assess the difference among various treatments based on the least significant difference (LSD at $p=0.05$ ).

\section{Results}

\subsection{Paddy Field Surface Flatness}

The paddy field surface flatness $2 \mathrm{~h}$ after field leveling is shown in Figure 3. In general, the mean flatness was less than $3 \mathrm{~cm}$ under all the three leveling treatments, which met the national standards. The higher flatness for DR + ML treatment can be explained by the multiple operations, which complete the basal dressing, straw returning by rotary tillage, and field leveling at one time, while under TT and DR treatment, the leveling process requires continuous leveling operations to achieve a better surface flatness. 


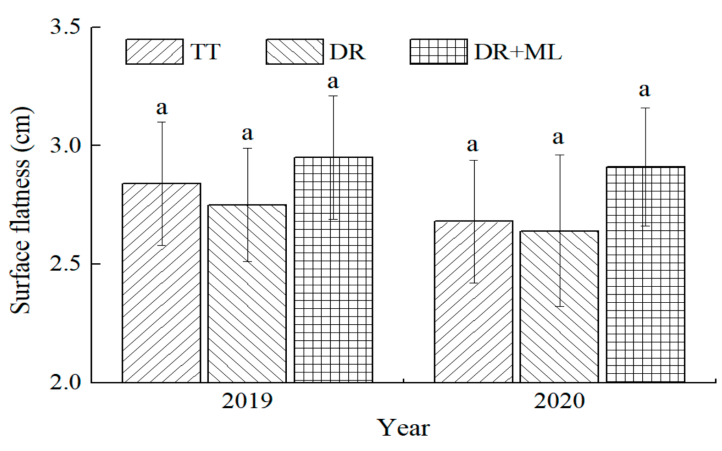

Figure 3. Surface flatness after paddy field leveling under TT, DR, and DR + ML treatments. TT = traditional tillage. $\mathrm{DR}=$ double axis rotary tillage. $\mathrm{DR}+\mathrm{ML}=$ multiple operations combined basal dressing, double axis rotary tillage, and paddy field leveling. Mean values in the same year followed by a same letter are not statistically different according to least significant difference (LSD) test $(p=0.05)$.

\subsection{Growing Stage}

In each cultivation season, the rice was sown and harvested at the same time to ensure a consistent growth duration. The growth stage and cultivation management was shown in Table 3. Compared with DR + ML treatment, TT and DR delayed the transplanting date for rice seedlings, resulting in a 5-6 days' shortening of the main growth period in field (from transplanting to harvesting). Moreover, the key growth stage (e.g., jointing and maturity) under TT and DR treatments appeared to be postponed accordingly. This may be attributed to the multiple operations of $\mathrm{DR}+\mathrm{ML}$, which reduced the operation procedures in paddy field preparation, saved leveling time, and ensures the timely transplanting for rice seedlings.

Table 3. Effects of paddy field soil preparation methods on growth stage and cultivation management for rice.

\begin{tabular}{ccccccccc}
\hline Year & Treatments & $\begin{array}{c}\text { Sowing } \\
\text { Date }\end{array}$ & $\begin{array}{c}\text { Transplanting } \\
\text { Date }\end{array}$ & Jointing & Maturity & Harvesting & $\begin{array}{c}\text { Total Growth } \\
\text { Period (d) }\end{array}$ & $\begin{array}{c}\text { Main Growth } \\
\text { Period (d) }\end{array}$ \\
\hline \multirow{2}{*}{2019} & TT & $5-23$ & $6-14$ & $7-30$ & $10-15$ & $10-19$ & 149 & 127 \\
& DR & $5-23$ & $6-14$ & $7-29$ & $10-12$ & $10-19$ & 149 & 127 \\
& DR + ML & $5-23$ & $6-09$ & $7-26$ & $10-10$ & $10-19$ & 149 & 132 \\
\hline \multirow{2}{*}{2020} & TT & $5-28$ & $6-23$ & $8-03$ & $10-22$ & $10-26$ & 151 & 125 \\
& DR & $5-28$ & $6-23$ & $7-31$ & $10-21$ & $10-26$ & 151 & 151 \\
\hline
\end{tabular}

Note: $\mathrm{TT}=$ traditional tillage. $\mathrm{DR}=$ double axis rotary tillage. $\mathrm{DR}+\mathrm{ML}=$ multiple operations combined basal dressing, double axis rotary tillage, and paddy field leveling.

\subsection{Plant Height}

At maturity stage, the rice plant height showed a similar trend in both of 2019 and 2020, i.e., $\mathrm{DR}+\mathrm{ML}>\mathrm{DR}>\mathrm{TT}$ (Figure 4). Compared with TT treatment, DR + ML increased plant height by $>3.3 \%$ in these two cultivation seasons $(p=0.05)$. Furthermore, DR treatment also tended to promote crop development, a significant improvement in plant height by $2.8 \%$ was observed in the second growing season $(p=0.05)$. 


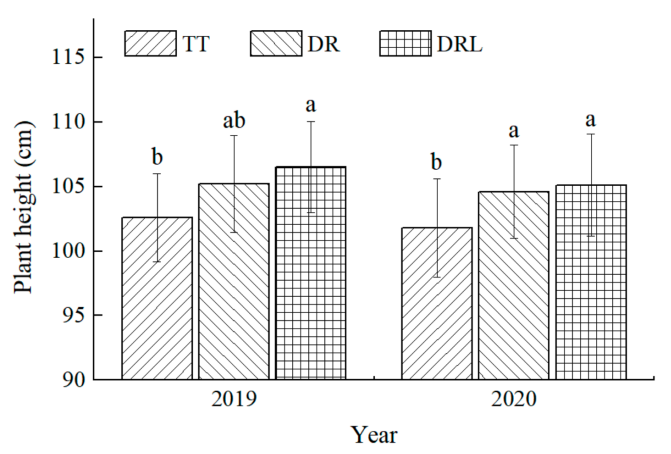

Figure 4. Plant height after paddy field leveling under TT, DR, and DR + ML treatments. TT = traditional tillage. $\mathrm{DR}=$ double axis rotary tillage. $\mathrm{DR}+\mathrm{ML}=$ multiple operations combined basal dressing, double axis rotary tillage, and paddy field leveling. The data were measured at maturity stage. Mean values in the same year followed by a different letter are statistically different at the 0.05 probability level according to least significant difference (LSD) test.

\section{4. $D M A$}

Crop DMA at key growing stages gradually increased over time (Figure 5). In the cropping seasons of 2019 and 2020, DMA also showed a similar trend, the DR + ML treatment tended to have the greatest DMA, while TT treatment showed the least, i.e., DR $+\mathrm{ML}>\mathrm{DR}>\mathrm{TT}$. Throughout the experimental period, a significant improvement for DMA was observed by $3.4-12.7 \%$ in DR + ML as compared with TT treatment $(p=0.05)$. Despite no significant difference in 2019, DR had greater DMA at the heading and maturity stages in the second season (2020), by $4.6 \%$ and $4.1 \%$, respectively, than that in TT treatment $(p=0.05)$.

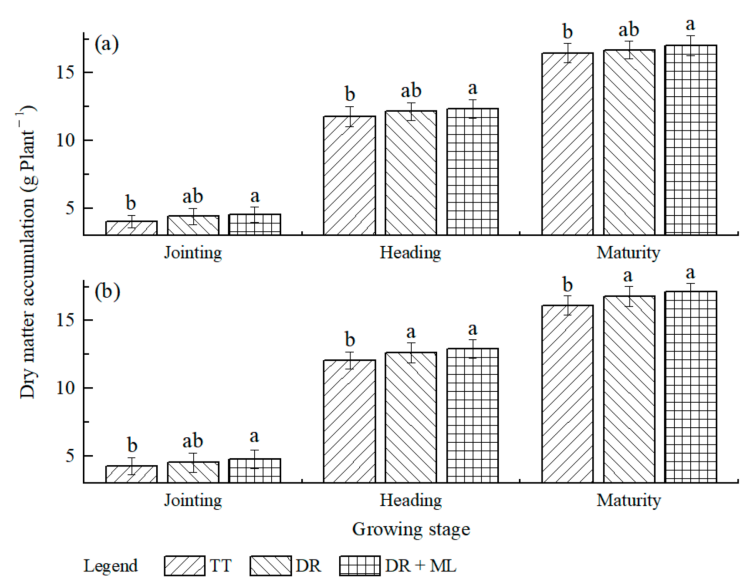

Figure 5. Dry matter accumulation (DMA) of rice under traditional tillage (TT), double axis rotary tillage (DR), and multiple operations combined basal dressing, double axis rotary tillage, and paddy field leveling (DR + ML) treatments at key growing stage in the 2019 (a), and 2020 (b) seasons. Mean values within same growing stage in the same year followed by a different letter are statistically different at the 0.05 probability level according to least significant difference (LSD) test.

\subsection{Grain Yield and Its Components}

Table 4 showed the influence of paddy field soil preparation methods on grain yield and its components. Generally, the DR + ML treatment tended to have the highest yield throughout the 2-year experimental period, while TT treatment had the least value, i.e., DR $+\mathrm{ML}>\mathrm{DR}>\mathrm{TT}$. Actual grain yield increased by $12.5 \%$ in 2019 and by $21.4 \%$ in 2020 under $\mathrm{DR}+\mathrm{ML}$ treatment in comparison to TT treatment $(p=0.05)$. From the analysis of yield components, no significant difference was observed in the number of panicles, spikelets per panicle, seed setting rate and thousand-grain quality among various methods. The 
difference in yield may come from the total spikelet amount (number of panicle $\times$ number of spikelets per panicle), which was $19.6 \%$ in 2019, and $21.3 \%$ in 2020 higher for DR + ML when compared with TT treatment $(p=0.05)$.

Table 4. Effect of different paddy field soil preparation methods on grain yield and its components. Values within the same component in the same year followed by a different letter are statistically different at the 0.05 probability level according to the least significant difference test.

\begin{tabular}{|c|c|c|c|c|c|c|c|}
\hline Year & Treatment & $\begin{array}{c}\text { No. of Panicle } \\
\left(10^{4} / \mathrm{hm}^{2}\right)\end{array}$ & $\begin{array}{l}\text { Spikelets (No. } \\
\text { per Panicle) }\end{array}$ & $\begin{array}{c}\text { Total Spikelets } \\
\left(10^{8} / \mathrm{hm}^{2}\right)\end{array}$ & $\begin{array}{c}\text { Seed Setting } \\
\text { Rate }(\%)\end{array}$ & $\begin{array}{l}\text { 1000-Grain } \\
\text { Weight (g) }\end{array}$ & $\begin{array}{c}\text { Actual Grain } \\
\text { Yield }\left(\mathrm{kg} / \mathrm{hm}^{2}\right)\end{array}$ \\
\hline \multirow{3}{*}{2019} & TT & $242 \mathrm{a}$ & $124 \mathrm{a}$ & $3.01 \mathrm{~b}$ & $92.6 \mathrm{a}$ & $26.57 \mathrm{a}$ & $6947 b$ \\
\hline & DR & $258 \mathrm{a}$ & $122 \mathrm{a}$ & $3.16 \mathrm{~b}$ & $93.0 \mathrm{a}$ & $27.09 \mathrm{a}$ & $7502 \mathrm{ab}$ \\
\hline & $\mathrm{DR}+\mathrm{ML}$ & $279 a$ & $129 \mathrm{a}$ & $3.60 \mathrm{a}$ & $93.2 \mathrm{a}$ & $27.13 \mathrm{a}$ & $7818 \mathrm{a}$ \\
\hline \multirow{3}{*}{2020} & $\mathrm{TT}$ & $248 \mathrm{a}$ & $123 a$ & $3.05 \mathrm{~b}$ & $91.1 \mathrm{a}$ & $26.32 \mathrm{a}$ & $6806 \mathrm{~b}$ \\
\hline & DR & $256 a$ & $129 a$ & $3.29 \mathrm{~b}$ & $92.9 \mathrm{a}$ & $27.13 \mathrm{a}$ & $7746 \mathrm{ab}$ \\
\hline & $\mathrm{DR}+\mathrm{ML}$ & $283 \mathrm{a}$ & $131 \mathrm{a}$ & $3.70 \mathrm{a}$ & $91.7 \mathrm{a}$ & $27.36 \mathrm{a}$ & 8267 a \\
\hline
\end{tabular}

Note: $\mathrm{TT}=$ traditional tillage. $\mathrm{DR}=$ double axis rotary tillage. $\mathrm{DR}+\mathrm{ML}=$ multiple operations combined basal dressing, double axis rotary tillage, and paddy field leveling. The total spikelet $=$ number of panicle $\times$ number of spikelet per panicle.

\subsection{Soil Bulk Density}

Soil bulk density showed an increasing trend with the increase of soil depth (Figure 6). Specifically, mean bulk density for TT, DR, and DR + ML treatments increased from 1361, 1320 , and $1284 \mathrm{~kg} \mathrm{~m}^{-3}$ to 1402,1362 , and $1324 \mathrm{~kg} \mathrm{~m}^{-3}$, respectively. Meanwhile, in the top $15 \mathrm{~cm}$ soil layer, bulk density showed TT $>$ DR $>$ DR + ML, but the difference was not significant. At $15-30 \mathrm{~cm}$ soil depth, mean values were similar to that of top $15 \mathrm{~cm}$. Furthermore, compared with TT treatment, DR + ML reduced the soil bulk density by $5.6 \%$ in 15 to $30 \mathrm{~cm}$ layer $(p=0.05)$.

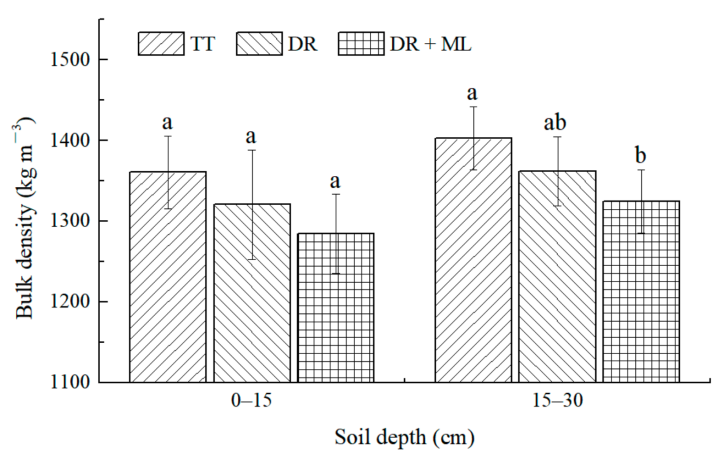

Figure 6. Mean soil bulk density to the depth of $0.30 \mathrm{~m}$ for traditional tillage (TT), double axis rotary tillage (DR), and multiple operations combined basal dressing, double axis rotary tillage, and paddy field leveling $(D R+M L)$ treatments in 2020. The data were measured on the fifth day after rice harvesting (without rainfall event). Means within the same soil depth followed by a different letter are statistically different at the 0.05 probability level according to the least significant difference (LSD) test.

\subsection{Economic Benefit}

Total input costs averaged 11,925 Yuan $\mathrm{hm}^{-2}$ for TT, 12,075 Yuan $\mathrm{hm}^{-2}$ for DR, and 11,175 Yuan $\mathrm{hm}^{-2}$ for DR + ML treatment. The reduction in DR + ML input costs was due to reduced mechanical operations for paddy field soil preparation (Table 5). Meanwhile, due to the increase in grain yield, the income, i.e., production value was $18,568 \mathrm{Yuan} \mathrm{hm}^{-2}$ for TT, 20,585 Yuan $\mathrm{hm}^{-2}$ for DR, and 21,716 Yuan hm ${ }^{-2}$ for DR + ML, which for DR + ML was a $17 \%$ and for DR was a $10.9 \%$ improvement in production value as compared with TT. When the saving in input and enrichment in crop yield were aggregated, DR + ML was $58.7 \%$ (by 3898 Yuan $\mathrm{hm}^{-2}$ ) more profitable than TT treatment. 
Table 5. Economic benefit analysis for traditional tillage (TT), double axis rotary tillage (DR), and multiple operations combined double axis rotary tillage and paddy field leveling (DR + ML) treatments. The data are mean values of 2019 and 2020 cultivation seasons. The labor cost is included in the mechanical operation.

\begin{tabular}{|c|c|c|c|}
\hline \multirow{2}{*}{ Items } & \multicolumn{3}{|c|}{ Treatments } \\
\hline & TT & DR & $\mathrm{DR}+\mathrm{ML}$ \\
\hline \multicolumn{4}{|l|}{ Input } \\
\hline $\begin{array}{l}\text { Mechanical operation cost for paddy } \\
\text { field soil preparation }{ }^{\dagger}\left(Y u a n / \mathrm{hm}^{2}\right)\end{array}$ & 1500 & 1650 & 750 \\
\hline $\begin{array}{c}\text { Mechanical operation cost for } \\
\text { transplant, plant protection and } \\
\left.\text { harvest (Yuan } / \mathrm{hm}^{2}\right)\end{array}$ & 1800 & 1800 & 1800 \\
\hline Materials $\ddagger\left(\right.$ Yuan $\left./ \mathrm{hm}^{2}\right)$ & 7275 & 7275 & 7275 \\
\hline Water management (Yuan $/ \mathrm{hm}^{2}$ ) & 1350 & 1350 & 1350 \\
\hline Total input & 11,925 & 12,075 & 11,175 \\
\hline \multicolumn{4}{|l|}{ Output } \\
\hline Yield $\left(\mathrm{kg} / \mathrm{hm}^{2}\right)$ & 6877 & 7624 & 8043 \\
\hline Production value (Yuan $/ \mathrm{hm}^{2}$ ) & 18,568 & 20,585 & 21,716 \\
\hline Economic benefit (Yuan $/ \mathrm{hm}^{2}$ ) & 6643 & 8510 & 10,541 \\
\hline
\end{tabular}

${ }^{\dagger}$ : Paddy field soil preparation is described in Table 2. ${ }^{\ddagger}$ : Input of materials includes 825 Yuan $\mathrm{hm}^{-2}$ of seed, $3675 \mathrm{Yuan} \mathrm{hm}^{-2}$ of Fertilize, and $2775 \mathrm{Yuan} \mathrm{hm}^{-2}$ of herbicides, insecticides and fungicides.

\section{Discussion}

Straw returning, an important agricultural measure to improve soil fertility and prevent air pollution caused by straw burning, has been widely implemented [22,23]. However, under the multiple cropping system of southern China, the $100 \%$ returning the previous crop straw to the field tends to result in extensive cultivation management and poor quality of land preparation. Moreover, the seedling transplanting is significantly delayed by multiple adversities, which are caused by superabundant straw, scarce labor, and short crop rotation time $[24,25]$. Therefore, this study differed from previous ones dramatically. Firstly, a multiple leveling technique for paddy field preparation was proposed, and the feasibility of this technique was verified by analyzing the physical properties of the leveled soil. Secondly, growing indicators at the key growing stage were compared under the same growth duration so as to summarize the potential benefits.

It was reported that appropriate tillage methods can enhance grain quality and improve soil fertility [26]. During the traditional paddy field preparation, farmers need to successfully complete the multichannel working procedures such as basal fertilizer application, water retting, straw returning by rotary tillage, and land leveling. The proportion of straw in topsoil tends to be higher after the residue incorporation because of the shallow rotary tillage depth. Double axis rotary tillage optimizes the plowing process, and the superabundant residues can be mixed into a deeper soil layer by increasing tillage depth and mixing the residues twice. This improvement can be confirmed by the decreased soil bulk density (DR + ML treatment in Figure 6, $p=0.05$ ). Furthermore, no statistical difference was observed between NT and DR treatments; this may result from the continuous leveling operations to achieve a standard-compliant surface flatness for paddy lands.

In addition, depending on the advantages of double axis rotary tillage, multiple field preparation completes the basal dressing, straw returning, and paddy land leveling once. The results showed that multiple field preparation provided an acceptable paddy field flatness in comparison to the TT treatment. More importantly, benefited from the simplified operating procedures, rice seedlings can be transplanted timely under DR + ML treatment, while the growth stage under TT and DR was delayed. Despite the same total growth duration, the growth period in the field (i.e., from transplanting to harvesting) under the TT and DR treatments were shortened by 5-6 days, which may directly lead to the delay of the maturity stage and the reduction of yield. 
For rice cultivation, panicle amount, spikelet per panicle, seed setting rate, and 1000 -grain weight are four vital components of yield [27,28]. It is generally agreed that the total spikelet amount (number of panicle $\times$ number of spikelet per panicle) is the key to increasing grain yield, under stable seed setting rate and 1000-grain weight condition $[29,30]$. In this study, despite no significant difference in panicle amount, spikelet per panicle, seed setting rate, and 1000-grain weight under these three treatments, the improvement in grain yield for DR + ML can be attributed to the $20.9 \%$ increase in 2-year mean total spikelet amount; a positive correlation was observed between total spikelet amount and grain yield, with a significant correlation coefficient of $0.729(p=0.05$; Figure 7).

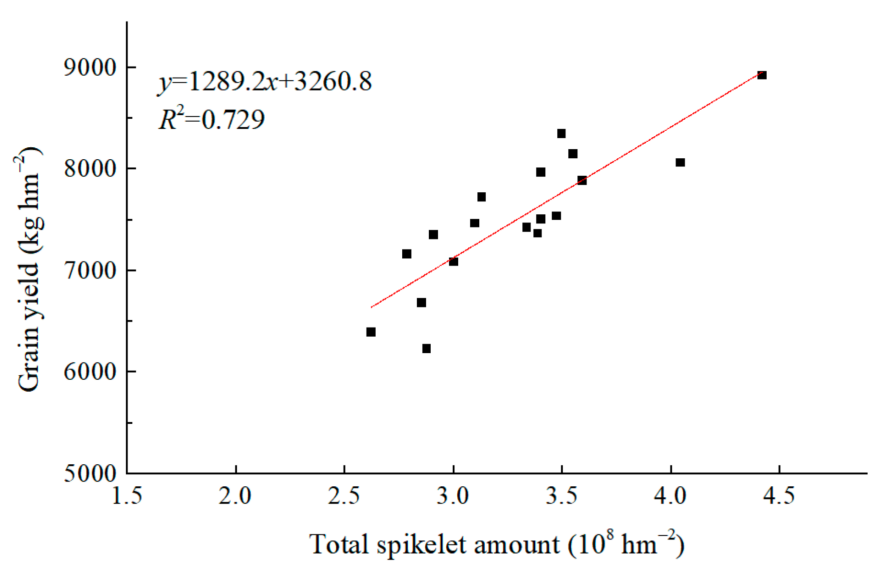

Figure 7. Relationship between total spikelet amount (number of panicle $\times$ number of spikelets per panicle) and grain yield.

In addition, the DMA after the heading stage is an important indicator to measure the rice population quality [31]. Stimulating DMA is beneficial to increase the grain yield, as the grain yield is linearly related to the dry matter quality at heading to maturity stage [32]. Similar results were also observed in this study. The DMA was significantly improved under the DR + ML method treatment $(p=0.05$; Figure 5).

In this study, we focused on the feasibility of multiple field preparation in improving the economic benefits of rice cultivation. Comprehensive economic benefits are obtained by subtracting input from total revenue. The results showed that economic benefits under the multiple field preparation were reflected in two aspects: firstly, a reduction of the cost of mechanical operation by simplifying the leveling procedures on the basis of ensuring the quality of the paddy field preparation; and secondly, improving the farmland output by accelerating the population quality of rice. Compared with traditional paddy field preparation methods (TT treatment), DR + ML increased the comprehensive economic benefits by 3989 Yuan per hectare. The results confirm our hypotheses and give a quantitative interpretation in comparison to local traditional agronomic practice.

However, there are several limitations to this research. First, despite the advantage in simplifying the working process and assuring leveling quality, i.e., flatness, there is a lack of follow-up in-depth testing for the physicochemical properties of the leveled soil. Farmland cultivation is a complex bio-system engineering, and any unnoticed factor will restrict the final output. Second, in the multiple cropping system, the comprehensive benefits under whole annual cultivation are requisite. Results reported here are insufficient to understand the economic status of rice-wheat cultivation without support from annual information in southern China.

Therefore, an interdisciplinary discussion would also augment the potential value of these findings. It is not an immediate approach, and the research will continue to be implemented to realize harmless returning of crop straw, thereby increased profit. Future studies will focus on a multidimensional analysis of multiple cropping of annual cultivation in terms of soil, crop, rhizospheric environment, annualized earnings, etc. 


\section{Conclusions}

In this study, 2-year rice cultivation experiments were conducted in a rice-wheat double cropping system, and the multiple paddy field preparation (DR + ML treatment) method was investigated to determine how it contributes to crop performance and economic profit.

The results showed that despite the simplified work process, the leveling flatness for the paddy field was equivalent in DR + ML treatment in comparison to TT treatment. Within the same growing duration, DR + ML treatment reduced the paddy field preparation time and extend the growing time in the field by 5-6 days. Furthermore, DR + ML showed advantages in stimulating plant height by $>3.3 \%$, increasing DMA by $3.4-12.7 \%$, and thereby $>12 \%$ advancement in grain yield was observed in comparison to TT. More importantly, we achieved an increase in total profit by 3898 Yuan per hectare. Results in this paper could provide an efficient demonstration for simplified high yield cultivation techniques in rice-related multiple cropping systems.

Author Contributions: Conceptualization, Y.Z. and W.Y.; methodology, Y.Z. and J.L.; software, J.L. and W.Y.; validation, Y.Z. and X.X.; formal analysis, J.L.; investigation, X.X. and J.L.; resources, R.Z.; data curation, J.L. and W.Y.; writing-original draft preparation, Y.Z.; writing-review and editing, Y.Z. and J.L.; visualization, R.Z. and X.X.; supervision, W.Y.; project administration, R.Z.; funding acquisition, Y.Z. and R.Z. All authors have read and agreed to the published version of the manuscript.

Funding: This research was funded by the Natural Science Foundation of the Jiangsu Higher Education Institutions (20KJB416008), the Interdisciplinary Project of Yangzhou University Crop Science Special Zone (yzuxk202007).

Institutional Review Board Statement: Not applicable.

Informed Consent Statement: Not applicable.

Data Availability Statement: Data contained within the article.

Acknowledgments: The authors would like to thank the technical support from their teacher and supervisor. We also appreciate the assistance provided by team members during the experiments. Additionally, we sincerely appreciate the work of the editor and the anonymous reviewers for the present paper.

Conflicts of Interest: The authors declare no conflict of interest.

\section{References}

1. Guan, C.Y.; Huang, H.; Huang, G.Q.; Sun, D.P.; Liang, Y.G. Problems and countermeasures of paddy field multiple cropping in southern China. Crops 2016, 171, 1-7. (In Chinese)

2. Xu, L.; Yang, M. Paddy Rice Production Mechanization in China-A Review. Ama-Agric. Mech. Asian Afr. $2014,45,7-11$.

3. Devkota, K.P.; Yadav, S.; Humphreys, E.; Kumar, A.; Kumar, P.; Kumar, V.; Malik, R.K.; Srivastava, A.K. Land gradient and configuration effects on yield, irrigation amount and irrigation water productivity in rice-wheat and maize-wheat cropping systems in Eastern India. Agric. Water Manag. 2021, 255, 107036. [CrossRef]

4. Agarwal, M.C.; Goel, A.C. Effect of field levelling quality on irrigation efficiency and crop yield. Agric. Water Manag. 1981, 4, 457-464. [CrossRef]

5. Iskandar, A.; Mehmood, U.H.; Kahramon, J. Water saving and economic impacts of land leveling: The case study of cotton production in Tajikistan. Irrig. Drain. Syst. 2007, 21, 251-263.

6. Jung, K.Y.; Choi, Y.D.; Lee, S.; Chun, H.G.; Kang, H.W. Spatial Analyses of Soil Chemical Properties from a Remodeled Paddy Field as Affected by Wet Land Leveling. Korean J. Soil Sci. Fertil. 2016, 49, 555-563. [CrossRef]

7. Osari, H. A new method for assessing land leveling to produce high quality consolidated paddy fields. Paddy Water Environ. 2003, 1, 35-41. [CrossRef]

8. Anwar, A.A.; Ahmad, W. Precision surface irrigation with conjunctive water use. Sustain. Water Resour. Manag. 2020, 6, 75. [CrossRef]

9. Chen, J.; Zhao, Z.; Chen, J.; Yu, L.; Ye, J. Design of nonlinear leveling control system for paddy land leveler. Trans. Chin. Soc. Agric. Mach. 2014, 45, 79-84. (In Chinese)

10. Quirós-Vargas, J.; Romanelli, T.L.; Rascher, U.; Agüero, J. Sustainability Performance through Technology Adoption: A Case Study of Land Leveling in a Paddy Field. Agronomy 2020, 10, 1681. [CrossRef] 
11. Hu, L.; Lin, C.; Luo, X.; Yang, W.; Xu, Y.; Zhou, H.; Zhang, Z. Design and experiment on auto leveling control system of agricultural implements. Trans. Chin. Soc. Agric. Eng. 2015, 31, 15-20. (In Chinese)

12. Tang, L.; Hu, L.; Zang, Y.; Luo, X.; Zhou, H.; Zhao, R.; He, J. Method and experiment for height measurement of scraper with water surface as benchmark in paddy field. Comput. Electron. Agric. 2018, 152, 198-205. [CrossRef]

13. Zhou, H.; Hu, L.; Luo, X.W.; Tang, L.M.; Du, P.; Mao, T.; Zhao, R.M.; He, J. Design and test of laser-controlled paddy field levelling-beater. Int. J. Agric. Biol. Eng. 2020, 13, 57-65. [CrossRef]

14. Aryal, J.P.; Mehrotra, M.B.; Jat, M.L.; Sidhu, H.S. Impacts of laser land leveling in rice-wheat systems of the north-western indo-gangetic plains of India. Food Secur. 2015, 7, 725-738. [CrossRef]

15. Xu, C.; Zhang, C.; Li, L.; Li, M. Optimization of working parameters for puddling and flatting machine in paddy field. Int. J. Agric. Biol. Eng. 2016, 9, 88-96.

16. Zhou, J.; Xu, J.; Wang, Y.; Liang, Y. Development of paddy field rotary-leveling machine based on GNSS. Trans. Chin. Soc. Agric. Mach. 2020, 51, 38-43. (In Chinese)

17. Hu, L.; Xu, Y.; He, J.; Du, P.; Zhao, R.; Luo, X. Design and Test of Tractor-Attached Laser-Controlled Rotary Scraper Land Leveler for Paddy Fields. J. Irrig. Drain. Eng. 2020, 146, 04020002. [CrossRef]

18. Zhang, H.; Yang, J.; Chen, M.; Huang, T.; Miao, L. Design and calibration of a rotating laser transmitter for fast and high-precision laser self-levelling system. Measurement 2021, 171, 108850. [CrossRef]

19. Hu, L.; Yang, W.; He, J.; Zhou, H.; Zhang, Z.; Luo, X.; Zhao, R.; Tang, L.; Du, P. Roll angle estimation using low cost MEMS sensors for paddy field machine. Comput. Electron Agric. 2019, 158, 183-188. [CrossRef]

20. Wang, L.; Xi, X.; Shan, X.; Qiu, W.; Wang, M.; Zhang, J.; Zhang, R. Design of compound paddy field soil preparation machine with double-axis rotary and automatic leveling devices. J. Yangzhou Univ. (Nat. Sci. Ed.) 2020, 23, 24-28. (In Chinese)

21. Jamil, I.; Jun, W.; Mughal, B.; Waheed, J.; Hussain, H.; Waseem, M. Agricultural innovation: A comparative analysis of economic benefits gained by farmers under climate resilient and conventional agricultural practices. Land Use Policy 2021, $108,105581$. [CrossRef]

22. Xing, Z.; Hu, Y.; Qian, H.; Cao, W.; Guo, B.; Wei, H.; Xu, K.; Huo, Z.; Zhou, G.; Dai, Q.; et al. Comparison of yield traits in rice among three mechanized planting methods in a rice-wheat rotation system. J. Integr. Agric. 2017, 16, 1451-1466. [CrossRef]

23. Gao, L.; Ma, L.; Zhang, W.; Wang, F.; Ma, W.; Zhang, F. Estimation of nutrient resource quantity of crop straw and its utilization situation in China. Trans. Chin. Soc. Agric. Eng. 2009, 25, 173-179. (In Chinese)

24. Xu, C.; Yuan, Q.; Zhao, S.; He, T.; Song, N. Effects of pretreatments on physical and chemical characteristics of wheat straw used as a maintenance-free compressed green roof substrate material. J. Clean. Prod. 2020, 227, 113381. [CrossRef]

25. Zhang, H.; Xing, Z.; Wen, W.; Tian, J.; Tao, Y.; Cheng, S.; Hu, Q.; Hu, Y.; Guo, B.; Wei, H. Growth Characteristics and Key Techniques for Stable Yield of Growth Constrained Direct Seeding Rice. Sci. Agric. Sin. 2021, 54, 1322-1337. (In Chinese)

26. Du, P.; Luo, H.W.; He, L.X.; Mao, T.; Lai, R.F.; Tang, X.R.; Tang, Q.Y.; Hu, L. The effect of plough tillage on productivity of ratooning rice system and soil organic matter. Appl. Ecol. Environ. Res. 2019, 17, 7641-7647. [CrossRef]

27. Pan, S.; Wen, X.; Wang, Z.; Ashraf, U.; Tian, H.; Duan, M.; Mo, Z.; Fan, P.; Tang, X. Benefits of mechanized deep placement of nitrogen fertilizer in direct-seeded rice in South China. Field Crops Res. 2017, 203, 139-149. [CrossRef]

28. Dou, Z.; Li, Y.; Guo, H.; Chen, L.; Jiang, J.; Zhou, Y.; Xu, Q.; Xing, Z.; Gao, H.; Zhang, H. Effects of mechanically transplanting methods and planting densities on yield and quality of Nanjing 2728 under rice-crayfish continuous production system. Agronomy 2021, 11, 488. [CrossRef]

29. Xie, X.; Shan, S.; Wang, Y.; Cao, F.; Chen, J.; Huang, M.; Zou, Y. Dense planting with reducing nitrogen rate increased grain yield and nitrogen use efficiency in two hybrid rice varieties across two light conditions. Field Crops Res. 2019, 236, 24-32. [CrossRef]

30. Hu, Y.; Cong, S.; Zhang, H. Comparison of the Grain Quality and Starch Physicochemical Properties between Japonica Rice Cultivars with Different Contents of Amylose, as Affected by Nitrogen Fertilization. Agronomy 2021, 11, 11070616. [CrossRef]

31. Ling, C.; Su, Z.; Zhang, H. Relationship between earbearing tiller percentage and population quality and its influential factors in rice. Acta Agron. Sin. 1995, 21, 463-469. (In Chinese)

32. Zhang, H.; Yu, C.; Chen, K.; Kong, X.; Liu, H.; Chen, J.; Gu, J.; Liu, L.; Wang, Z.; Yang, J. Effect of direct-seeding methods on physiological characteristics and grain yield of rice and its cost analysis. Trans. Chin. Soc. Agric. Eng. 2017, 33, 58-64. (In Chinese) 